\title{
0 trabalho do pedagogo nos IFs: uma busca pela qualidade da educação profissional tecnológica
}

Pedagogue's work in Fls: a search for the quality of professional education technology

Andressa Graziele Brandt, andressa@ifc-riodosul.edu.br

Franc-Lane Sousa Carvalho Nascimento, franclanecarvalhon@gmail.com

Nadja Regina Sousa Magalhães, nadjamagalhaes@yahoo.com.br

Marylucia Cavalcante Silva, marynead@yahoo.com.br

Resumo: Neste artigo, discutimos as atribuições, saberes e condições de trabalho do pedagogo da educação profissional do Instituto Federal de Educação, Ciência e Tecnologia de Santa Catarina - IFs, tendo em vista as contribuições desse profissional na implementação de uma educação de qualidade. Delimitamos os seguintes objetivos: investigar as atribuições e contribuições do pedagogo na educação profissional e refletir sobre as condições de trabalho visualizando a qualidade dos serviços prestados pelas supervisões pedagógicas. Nesse sentido, partimos do seguinte problema de pesquisa: Qual a influência da ação da supervisão pedagógica e a contribuição na construção de uma educação de qualidade nos IFs de SC? Fundamentamos esse estudo em pesquisadores, como: Placco (1994); Freire (1979); Orsolon (2003); Kuenzer (1999); e Severino (2003), entre outros. Esta pesquisa, de caráter qualitativo, está definida como um estudo de caso; assim, realizamos uma entrevista para levantar as informações pelos Pedagogos dos IFs. Os resultados apontaram que o supervisor educacional precisa ter conhecimento básico sobre os IFs, conhecimento sobre a legislação e o desenvolvimento humano, além de habilidades e competências, tais como: ser pesquisador da realidade educacional, fazer a releitura do seu cotidiano, promover mudanças necessárias, criar novos horizontes para a instituição, ter competência teórica para orientar o processo pedagógico, abrir possibilidade de diálogo entre o grupo, orientar seus colegas na construção da proposta pedagógica que dará identidade aos IFs, enfim, ser articulador do processo pedagógico e do Projeto Pedagógico.

Palavras-chave: Pedagogo; Educação Profissional Tecnológica; Qualidade.

\begin{abstract}
In this article, we discuss the assignments, contributions, knowledge and working conditions of the vocational education's pedagogue of the Federal Institute of Education, Science and Technology of Santa Catarina - Fls, considering the contributions of the teacher as a professional who helps in the implementation of quality education. We defined the following goals: investigate the assigns and contributions of the educator in professional education and reflect about the work conditions looking for the quality of services provided by pedagogical supervision. Therefore, we set the following research problem: What is the influence of the pedagogical supervision action and the contribution in building a quality education on Santa Catarina's Fls? We base this study in researchers as Placco (1994), Freire (1979); Orsolon (2003); Kuenzer (1999) and Severino (2003 ) among others. This research is defined as a case study of a qualitative character, so we did an interview to elicit information from pedagogues of Fls. The results showed that the educational supervisor needs the basic knowledge about the Fls, the legislation and the human development, as have skills and competencies like: be a researcher of educational reality, make the reading of his daily life, promote necessary changes, create new horizons for the institution, have theoretical competence to guide the educational process, open possibilities of dialogue among the group, guide his colleagues in the construction of a pedagogical proposal that will provide identity to the Fls, lastly, articulate the pedagogical process and the pedagogical project.
\end{abstract}

Keywords: Pedagogue; Vocational Education Technological; Quality. 
$\mathrm{N}^{2}$ presente trabalho, discutimos "O trabalho do pedagogo, suas atribuições, saberes e condições de trabaIho em favor da qualidade da educação profissional dos IFs". Dessa forma, partimos da investigação sobre as atribuições do pedagogo dos IFs de Santa Catarina (SC), para observar os seus saberes profissionais na educação profissional, a qualidade dos serviços prestados pelos pedagogos de algumas instituições federais de ensino, a influência da ação desses profissionais no desenvolvimento pedagógico nas instituições, verificando sua influência e contribuição na construção de uma educação de qualidade.

Nessa perspectiva, constatou-se que o pedagogo dos IFs executa a função de supervisão, com a proposta definida de organizar e sistematizar os diversos conhecimentos, saberes e princípios educativos advindos do processo de ensino e aprendizagem, de modo a contribuir com a transformação de uma educação de melhor qualidade. De acordo com Placco (1994), transformar significa ultrapassar o estabelecido, desmontar os antigos referenciais, adotar novas bases conceituais e metodológicas, construir novas modalidades de ação educativa, estabelecendo objetividade e subjetividade.

Assim, o pedagogo necessita acompanhar as atividades educacionais, visando direcionar e qualificar esse processo. Para tanto, é fundamental consolidar uma boa fundamentação teórica, conhecer a legislação educacional e ter capacidade de planejar, pois é por meio de um bom planejamento que a garantia de um trabalho mais qualificado ocorrerá, tendo como base o trabalho em equipe, que depende da interação com as demais pessoas e setores, assim como do envolvimento com a elaboração e/ou reestruturação de documentos que organizem o saber/fazer pedagógico.

Este estudo foi realizado nos IFs de SC. Partimos do seguinte problema de pesquisa: Qual a influência da ação do pedagogo e quais as suas contribuições na construção de uma educação de qualidade nos IFs de SC?

A pesquisa parte da problemática vivenciada pelos pedagogos que efetivam o trabalho de supervisão nos IFs, tendo como pressuposto as atribuições e os saberes do pedagogo no IF Catarinense e no IF de Santa Catarina e suas contribuições para a educação profissional de melhor qualidade. Para tanto, este estudo teve como base as leituras realizadas acerca do tema delimitado, definindo-se como estudo de caso e pesquisa qualitativa-descritiva, através de um estudo de caso, que utilizou entrevista, com o objetivo de levantar dados fornecidos pelo informante ou pesquisado, sem a assistência direta ou a orientação do investigador.

Especificamos o seguinte objetivo geral: investigar as atribuições e as contribuições dos Supervisores Educacionais nos IFs de SC na educação profissional de nível médio. Para tanto, buscamos atingir os seguintes objetivos específicos: identificar as atribuições e as contribuições do Pedagogo dos IFs de SC; caracterizar as ações do setor pedagógico das instituições IFs de SC, verificando as necessidades de melhoria; analisar as condições de trabalho, visualizando a qualidade dos serviços prestados pelas supervisões pedagógicas; e propor ações que visem ao aumento das contribuições pedagógicas desses profissionais nos institutos federais de ensino.

Essa pesquisa é importante pelas contribuições que serão oferecidas às instituições de ensino após o estudo da influência da ação e atribuições da supervisão pedagógica no nível de satisfação dos colaboradores das instituições de ensino, nas quais será realizado o trabalho. E, ainda, pela relevância acadêmica. Pretendemos também colaborar com as discussões referentes ao setor de supervisão pedagógica dos cursos profissionais dos IFs.

Compreendemos que para atingir a qualidade da educação é necessário um projeto de educação que entenda como compromisso de transformação/mudanças e de aprofundamento de conhecimentos objetivos capazes de modificar a vida social e de atribuir-Ihe maior sentido e alcance no conjunto da experiência humana. Esta proposta educativa é incompatível com uma visão conservadora de sociedade. A democratização de uma educação de qualidade é fundamental para o desenvolvimento de uma nação.

A transformação da educação de qualidade para todos exige ações consolidadas na melhoria das condições de trabalho do professor/supervisor, mais recursos financeiros para melhorar a infraestrutura das instituições, recursos didáticos, bibliotecas, formação docente consolidada em teorias críticas, buscando práticas de excelência que garantem e resultem na efetiva aprendizagem dos alunos.

O estudo divide-se em três momentos: o primeiro traz aportes teóricos sobre o trabalho dos pedagogos e as suas práticas pedagógicas; o segundo traz os dados da pesquisa, analisados de acordo com os teóricos investigados; e o terceiro e último momento traz as contribuições da pesquisa e conclusões do estudo.

\section{O PEDAGOGO, SUAS ATRIBUIÇÕES E CONTRIBUIÇÕES NAS PRÁTICAS PEDAGÓGICAS DOS IFS DE SC}

Tendo em vista a história da educação, o profissional Pedagogo que desenvolve a função de Supervisor Pedagógico inicia suas atividades no sistema educacional brasileiro na década de 20, inspiração dos trabalhos realizados nos Estados Unidos e na França. O espaço que o 
Pedagogo possui deve ser preenchido com uma atuação comprometida com as mudanças exigidas pela sociedade, com o papel que a escola deve desenvolver na concretização, transformação, criação, recriação, integração e universalização do saber.

Ao refletir sobre as práticas pedagógicas realizadas pela supervisão pedagógica, percebe-se como é necessário trabalhar intensamente com o grupo de professores, pois, à medida que o tempo vai passando, alguns colegas vão se adaptando e pensam que dispõem de um conhecimento completo e satisfatório e que não precisam aperfeiçoar-se, nem mesmo inovar a sua prática pedagógica. Por outro lado, há outros que se comprometem com uma prática pedagógica diferenciada, procurando motivar e auxiliar os colegas para a obtenção de resultados satisfatórios no processo ensino-aprendizagem.

$\mathrm{Na}$ atualidade, com o comprometimento da qualidade da educação pública, vem ocorrendo um direcionamento de propostas alternativas para a escola associado à urgência; segundo Rios (2001, p.21), de "[...] qualificar a qualidade, refletir sobre a significação de que ela se reveste no interior da prática educativa." São necessárias iniciativas que possam favorecer a consolidação de uma educação de qualidade, sendo preciso o envolvimento de todos nesse processo, inclusive do professor. Para que o desempenho escolar dos alunos alcancem melhores resultados, são necessários professores que sejam competentes, comprometidos e apoiados pedagogicamente pela direção da escola e pelos órgãos centrais.

Portanto, cabe ao poder público estabelecer políticas educacionais de formação de professores associadas à produção de conhecimento reflexivo, crítico, político e transformador, o que somente se conseguirá a partir da melhor qualidade da prática de ensino e aprendizagem, em todos os níveis do sistema público de ensino. À sociedade cabe assumir sua responsabilidade de participação na educação pública, pois essa é a principal forma de controle da qualidade das atividades pedagógicas desenvolvidas e da aplicação de recursos educacionais dentro de cada realidade.

Conforme nos diz Severino ( 2003) :

Tanto no que concerne à sua formação como à sua atuação profissional, o educador não se confunde com as figuras do pai e da mãe, do sacerdote, do engenheiro, do cientista, do filósofo, do psicoterapeuta. Ele é um "pedagogo", no sentido originário do termo. Se é verdade que a relação pedagógica tem muitos aspectos em comum com essas outras intervenções, ela não se identifica com nenhuma delas, não se exaure em nenhuma delas. De grande abrangência antropológica, a relação pedagógica envolve a totalidade da condição humana, implica todos os aspectos da existência das pessoas, serve-se de todos os seus recursos, mas configura-se numa especificidade própria, a da construção histórico-antropológica dos seres humanos, ao mediar a inserção das novas gerações no complexo universo das mediações do existir histórico-social (Severino, 2003, p.86-87).

Para tanto, é necessário que o Pedagogo redimensione o seu papel, fazendo o movimento de abandonar o seu fazer psicologizante, assumindo, assim, um fazer político-pedagógico. Placco (1994) aponta que o supervisor, ao assumir essa nova postura de educador comprometido com a formação do cidadão e a transformação social e da escola, assume uma nova identidade. Assim, a educação profissional deve ser discutida tendo:

[...] em vista as novas demandas de acumulação que deram origem a um novo regime fundado na flexibilização, configura-se uma nova concepção de educação profissional que, por conseqüência, traz novas demandas de formação de professores. Temos, portanto, sido solicitados a dar um salto de qualidade nesta formação, entendendo que a concepção da educação profissional e os espaços de atuação, a partir das mudanças ocorridas no mundo do trabalho, trazem novos desafios, tanto para o capital quanto para o trabalho. (KUENZER, FRANCO, MACHADO, 2008, P. 20)

Percebe-se que a tarefa do pedagogo da escola é árdua, pois é o articulador num grupo que mantém tantas diferenças de pensamentos, de caráter, atitudes e ações. Conforme Orsolon (2003, p. 22), "O coordenador, como um dos articuladores desse trabalho coletivo, precisa ser capaz de ler, observar e congregar as necessidades dos que atuam na escola e, nesse contexto, introduzir inovações para que todos se comprometam com a proposta". Acreditando nessa afirmação, percebe-se como complicada e difícil é a tarefa do pedagogo da escola, sendo a escola um ambiente com tantas diferenças e necessitando realizar um trabalho coletivo. Segundo Orsolon (2003, p. 19):

O coordenador é apenas um dos atores que compõem o coletivo da escola. Para coordenar, direcionando suas ações para a transformação, precisa estar consciente de que seu trabalho não se dá isoladamente, mas nesse coletivo, mediante a articulação dos diferentes atores escolares, no sentido da construção de um projeto político pedagógico transformador.

Portanto, cabe ao grupo da escola como um todo romper com paradigmas e engajar-se a uma prática pedagógica problematizadora e consciente, pois mesmo antes de ingressar na escola a criança já possui experiências anteriores e traz consigo uma bagagem de conhecimentos adquiridos na sua vivência, tornando-se impossível ignorá-los. Torna-se complexo, pois permite que o aluno seja o sujeito de sua 
história. Baseado nos fundamentos teóricos de Kuenzer, Franco e Machado (2008, p. 31), é "[...] possível compreender que a função dos profissionais da educação profissional é melhorar as condições dessa inclusão concedida, como limite de possibilidade, porém importante na luta pela construção de uma sociedade mais justa e igualitária."

Os estudos sobre formação, profissionalização e qualidade da educação apresentam controvérsias que ainda precisam ser analisadas. Segundo Paro (2001), a escola pública tem baixa qualidade, porque, em seus métodos e conteúdos, não favorece a atualização histórica e cultural do aluno, de modo a que este se construa como sujeito histórico e para a vivência da cidadania. É urgente a necessidade da consolidação de uma política pública que valorize a qualidade em detrimento da quantidade e que se efetivem as oportunidades sociais de forma que todos tenham melhor qualidade de vida.

Portanto, fica bem mais fácil transmitir ao aluno um conhecimento já pronto, acabado, com resultados certos. Reconhecer o aluno como um sujeito que constrói o seu conhecimento requer do professor mais estudo, mais pesquisa. Além disso, está sujeito à inquietação, à angústia e à insegurança, pois o aluno tem a oportunidade de questionar e criticar aquilo com que não concorda. Conforme afirma Freire (1979, p. 28-29):

A educação, portanto, implica uma busca realizada por um sujeito que é o homem. O homem deve ser o sujeito de sua própria educação. Não pode ser o objeto dela. Por isso, ninguém educa ninguém [...]. não podemos nos colocar na posição do ser superior que ensina um grupo de ignorantes, mas sim, na posição humilde daquele que comunica um saber relativo a outros que possuem outro saber relativo.

O pedagogo tem um papel fundamental na articulação desse processo - o de motivar os professores para a formação contínua. Essa formação depende das condições de trabalho oferecidas aos educadores, mas, principalmente, das atitudes destes diante do seu desenvolvimento profissional e emocional. Cada professor é responsável por esse processo de formação continuada, sendo extremamente importante o professor refletir sobre suas práticas pedagógicas, buscando fundamentação teórica para concretizar as mudanças. Mas, a mudança só será real se vier de dentro; "aprender" técnicas apenas para ter sucesso torna o processo artificial. C Conforme Moraes (2003, p. 189-190):

[...] Na realidade, sempre estamos emocionalmente envolvidos e comprometidos com um modelo conhecido, com um velho hábito, com uma prática ou com pessoas com as quais se convive. Velhos modelos, hábitos e tradições persistem o quanto podem, sustentados pela resistência que o ser humano tem para mudar, para se desfazer do velho e do conhecido, para abraçar o novo e desconhecido.

Por tanto, é necessário profissional especializado; é preciso que o Estado evidencie sua importância como articulador de políticas educacionais, pois, historicamente, a educação absorveu significados distintos de qualidade, construídos, condicionados pela oferta limitada de escolarização, definidos pela quantidade de alunos aprovados ou não. É a qualidade associada a medidas de desempenho. Concorda com essa posição Beisiegel (2006, p. 160) e acrescenta: "Não foram investidos no ensino os recursos exigidos pela dimensão do processo de democratização das oportunidades." A expansão da educação desenvolveu-se sob pressão social, o que ocasiona escassez de recursos materiais e humanos.

Tendo como base os problemas apresentados, relacionados à formação do professor e à implementação de políticas públicas que têm como prioridade a quantidade em detrimento da qualidade da educação, para Freire (1997, p. 50), é preciso "[...] trabalhar lucidamente em favor da escola pública, em favor da melhoria de seus padrões de ensino, em defesa da dignidade dos docentes, de sua formação permanente." A transformação dos padrões de quantidade e qualidade da educação para todos é necessária e urgente.

$\mathrm{Na}$ instituição educativa, devem ser mudadas as relações sociais e a forma de compreender o ato educativo, pois o desenvolvimento se efetiva pelo processo de reorganização e reconstrução da experiência. $\mathrm{O}$ ato educativo é contínuo e de transformação ao longo da vida. O pedagogo que exerce a supervisão nos IFs deve estar preparado teoricamente e metodologicamente para que possa superar os desafios e dificuldades.

Portanto, a prática pedagógica do Supervisor necessita estar voltada, tanto para o atendimento individualizado a professores, cujo principal objetivo é discutir questões relacionadas à sua prática pedagógica diária, quanto para a discussão de casos específicos trazidos pelos professores.

\footnotetext{
Assim é que as exigências para o exercício da docência nas universidades e Cefets, por exemplo, incluem qualificação específica em mestrado e em doutorado, tendo em vista o desenvolvimento da pesquisa, ou pelo menos em cursos de licenciatura, tendo em vista a capacitação para a docência, além da dedicação integral e exclusiva. Nestes casos, há planos de carreira e condições de trabalho que viabilizam a qualificação continuada, e assim, o exercício profissional qualificado. (KUENZER, FRANCO, MACHADO, 2008, p. 31)
}

Nesse sentido a supervisão pode contemplar: observação da prática pedagógica com devolutivas e encaminhamentos; 
direcionamento de estudos; orientação para planejamento; estudo e discussão de casos; elaboração de estratégias e objetivos para o trabalho; análise e reflexão da prática pedagógica; orientação em avaliações; indicações de bibliografias para estudo; orientação de projetos; orientação em como realizar o trabalho diversificado, etc.

Historicamente, o professor passou a ter no pedagogo um inimigo que inspecionava seu trabalho sem entender do conteúdo, mas que deveria dominar técnicas e metodologias de ensino e aprendizagem (BRZEZINSKI, 1996). Outra crítica direcionada ao pedagogo é a influência da psicologia numa identificação terapêutica, que considera o aluno como único responsável pelo sucesso ou fracasso; essas atribuições são mal definidas e conflitantes.

Portanto, a prática do pedagogo poderá partir de uma análise crítica voltada para a compreensão dos problemas. Assim, as soluções devem ser encontradas no coletivo, a partir de uma visão crítica, assumindo uma posição de compromisso ao acompanhar a organização do trabalho na escola. Para Villas Boas (2006), pensar a prática do pedagogo é, sobretudo, examiná-la nas funções em que se desenvolva. É analisá-la desde o planejamento do currículo, procedido por meio de diagnóstico, de acompanhamento e de sua execução, o que representa seu aperfeiçoamento, considerados os recursos humanos, materiais e técnicos empenhados.

O papel do pedagogo passa a ser redefinido com base em seu objeto de trabalho, e o resultado da relação que ocorre entre o professor que ensina e o aluno que aprende passa a constituir o núcleo do trabalho do supervisor na escola, sendo que: "[...] o pedagogo parte do esclarecimento a respeito da ação diária que caracteriza o trabaIho realizado na escola." (MEDINA, 1997, p. 34). O pedagogo deve incentivar a participação de todos no planejamento e discutir as diferentes formas de se encaminhar a aprendizagem dos alunos, buscando por meio do diálogo, caminhos próprios na intervenção da qualidade do trabaIho realizado pelo professor em sala de aula.

\section{Pressupostos METOdOLÓgICOS DA PESQUISA}

A pesquisa foi realizada a partir de leituras acerca do tema delimitado, seguindo os princípios epistemológicos de um estudo de caso e uma pesquisa qualitativo-descritiva.

O estudo de caso deve ser visto como um valor específico; o caso deve ser bem delimitado, tendo seus contornos claramente definidos no desenrolar do estudo. No processo de recolha de dados, o pesquisador recorre a várias técnicas próprias da investigação qualitativa, nomeadamente o diário de campo, a entrevista e a observação participante. Segundo Yin (2004, p.92), "A utilização de múltiplas fontes de dados na construção de um estudo de caso permitenos considerar um conjunto mais diversificado de tópicos de análise e em simultâneo permite corroborar o mesmo fenômeno".

As características do estudo de caso, segundo Lüdke e André (1986), visam à descoberta; enfatizam a interpretação em contexto real; buscam retratar a realidade de forma completa e profunda; utilizam uma variedade de fontes de informações; revelam experiências e procuram representar os diferentes e, às vezes, conflitantes pontos de vista presentes na situação social; utilizam uma linguagem e uma forma mais acessível do que os outros relatórios de pesquisa.O estudo de caso é um método teórico-prático utilizado nos estudos das diversas áreas do conhecimento.

Para Macedo (2006, p. 90), no estudo de caso, mais de uma realidade é estudada pontualmente; lança-se mão do denominado estudo sobre casos ou multicasos. Deve-se "[...] compreender uma instância singular, especial. O objeto estudado é tratado como único, idiográfico - mesmo quando compreendido como emergência relacional -, isto é, consubstancia-se numa totalidade complexa [...]". A preocupação é em resguardar a natureza idiográfica e relacional desses estudos, evitando a mera comparação dos fatos e buscando relações contrastantes e totalizantes do movimento relacional com os contextos.

As questões delimitadas para a entrevista tiveram sustentação nas questões norteadoras. Para André (1995, p. 28), "As entrevistas têm a finalidade de aprofundar as questões e esclarecer os problemas observados." Através das entrevistas, podemos aprofundar as questões analisadas, já que temos como reelaborar novas questões. As entrevistas configurar-se-ão como uma situação que facilitará o diálogo para uma posterior descrição e análise dos dados coletados ao longo da pesquisa.

Dessa forma, a pesquisa foi realizada tendo em vista a análise das atribuições, contribuições, saberes e condições de trabalho do pedagogo pela qualidade da educação profissional no Instituto Federal de Educação, Ciência e Tecnologia Catarinense - IF Catarinense e no Instituto Federal de Educação, Ciência e Tecnologia de Santa Catarina - IFSC, tendo como objetivo investigar e refletir sobre as atribuições e contribuições do pedagogo na educação profissional. 


\section{REVELAÇÕES DOS PEDAGOGOS SOBRE AS ATRIBUIÇÕES E CONTRIBUIÇÕES NA EDUCAÇÃO DE QUALIDADE NOS IFS}

Após coletar todas as informações para o desenvolvimento do estudo, faz-se necessário que estas sejam analisadas e interpretadas a fim de se conseguirem respostas ao problema proposto.

Ao serem questionados sobre as suas atribuições nos campi, os pedagogos entrevistados responderam ser do cotidiano desse profissional: planejar, organizar e executar ações didático-pedagógicas, visando à otimização dos recursos e à eficiência do processo ensino-aprendizagem e centrar-se no acompanhamento e assessoramento de todas as atividades didático-pedagógicas que envolvem setores e coordenações diretamente ligadas à parte pedagógica, além de docentes e discentes. No caso da assessoria discente: acompanhamento pedagógico (alunos com dificuldades de aprendizagem e outras); planejamento e realização de projetos; elaboração dos Planos de curso; elaboração dos Planos de Trabalho Individual dos docentes; orientações quanto à elaboração dos Planos de Ensino.

Os pedagogos também cuidam da organização didático-pedagógica dos cursos; planejamento e execução das Formações Continuadas Docentes; planejamento e organização das Avaliações Pedagógicas (Conselhos de Classe); participação em reuniões pedagógicas e de conselhos de classe; planejamento e organização das reuniões de pais; planejamento e acompanhamento das monitorias voluntárias; acolhimento e orientações aos novos docentes; elaboração de diretrizes para o processo ensino-aprendizagem; elaboração de documentos administrativos; acompanhamento do Livro-Diário; controle dos recursos audiovisuais; atendimento de balcão ao público interno; atendimento externo com informações relativas aos cursos ofertados e demais questões relativas ao ensino. Portanto, envolve planejamento, execução e avaliação das atividades pedagógicas, que incluem formação docente e discente. O projeto político-pedagógico da escola é uma tarefa da própria escola, nunca concluído, pois está constantemente se construindo de acordo com as necessidades da realidade.

Os envolvidos na dinâmica do ensino-aprendizagem, participantes na auto-reflexão do trabalho educativo, ato político-coletivo. A escola é, em última análise, uma proposta pedagógica. Trata-se de um aprender a fazer a leitura dessa proposta em sua intencionalidade, como condição de poder dela participar, no sentido de sua provisoriedade, retomando sempre, de novo, as questões substantivas da educação e as questões estratégicas de sua condução pedagógica. (GADOTTI, 2000. p. 68-69).
Já a respeito das principais contribuições para o desenvolvimento de uma educação profissional de qualidade, as respostas foram: manter o foco nas competências a serem desenvolvidas pelos alunos e acompanhar seu desempenho escolar, buscando a qualidade nos resultados do processo ensino-aprendizagem, e enxergar todo o processo educativo. Destacamos que toda articulação entre os setores envolvidos com a educação profissional é e deve ser do setor pedagógico da instituição, como forma de desencadear ações que estejam interligadas e inter-relacionadas.

Contudo, o pedagogo precisa ser um articulador e desencadeador da formação continuada e permanente dos profissionais da educação e preocupar-se com a formação discente - em todos os aspectos: como aluno, indivíduo e cidadão, para que este esteja preparado e obtenha sucesso na vida estudantil, profissional e pessoal. Além disso, também prestar contribuição na agilização de questões técnico-administrativas ligadas à área pedagógica, necessárias à educação de qualidade (construção de Projetos de Criação de Cursos - PCCs, Projetos Pedagógicos de Cursos - PPCs e outros documentos, organização de reuniões).

Quando questionados sobre que ações são feitas em seu campus para melhorar o trabalho realizado pelos educadores, obtivemos as seguintes respostas: formação de alunos comprometidos com o processo ensino-aprendizagem e conscientes do seu papel na escola e na sociedade facilita o trabalho dos educadores, avaliação continuada do processo ensino-aprendizagem, por meio de instrumentos como a Avaliação Discente, a Avaliação Pedagógica e o Livro-Diário, além do atendimento diário de pais, alunos e educadores; organização de horários; acompanhamento das viagens técnicas; organização das trocas de aulas; formação docente; formação discente; acompanhamento aos discentes; planejamento e execução de reuniões de pré-conselho, de conselho de classe, de professores e coordenadores, de atendimento aos docentes, de orientações aos pais dos discentes e de estudos de viabilidade de ações, entre tantas outras ações do dia a dia da instituição.

A democratização da escola não acontecerá de maneira isolada, mas, sim, paralelamente à democratização da sociedade, à medida que as pessoas buscam a transformação de sua prática cotidiana nos diferentes meios com que convivem. "Talvez se possa dizer: quando o cotidiano se torna democrático, é porque a democracia atingiu nível de cultura popular". (DEMO, 1999, p. 30). Para alcançarmos o objetivo da democratização da educação de qualidade, é necessária a garantia de políticas públicas favoráveis às reais necessidades das instituições formativas de todos os níveis de ensino, valorizando os ideários pedagógicos críticos. A instituição educativa pública, como parte de um contexto 
social, precisa estar atenta às mudanças relacionadas à construção do processo de democratização de uma educação de melhor qualidade, sendo imprescindível a participação dos envolvidos no processo. A qualidade pode ser entendida como oportunidade de emancipação do trabalho educativo, de forma que o aluno possa aprender.

É importante confirmar que a prática pedagógica e a formação de pedagogos devem estar inter-relacionadas, já que o sucesso do trabalho pedagógico depende de uma boa formação, ou seja, de um saber bem elaborado, que corresponda aos desafios e às expectativas da sociedade. A qualidade da educação está associada à aprendizagem e ao desenvolvimento social e emocional do aluno, o que requer do pedagogo/supervisor uma ampla visão sobre as constantes mudanças educacionais. Assim, esse profissional deve estar em permanente formação para que possa aperfeiçoar o seu trabalho.

O planejamento do setor pedagógico em relação às atividades realizadas na escola tem papel fundamental, pois é desse planejamento que surge o primordial para o sucesso dos serviços prestados pela instituição.

Esse planejamento implicará a organização da própria escola, refletindo-se na organização dos trabalhadores em geral e, "em primeiro lugar, passa pela percepção clara do que é ser trabalhador" (COBRA, 2002, p. 22).

Essa tarefa exige do pedagogo/supervisor uma estrutura organizacional eficiente dos dados, de forma que estes possam ser utilizados por todos aqueles que trabalham com os educandos nos IFs.

Quando foram questionados em relação às reuniões escolares realizadas e aos assuntos tratados nesses encontros - importantíssimos para os educadores da instituição, pois representam o contato direto entre escola, educadores e pais -, a maioria dos entrevistados disse que os acha péssimos. O supervisor deve estar aberto à mudança e à perspectiva de analisar seu trabalho e colher sugestões dos colegas sobre os assuntos que são importantes para a realidade.

Isso é um ponto fraco, pois esse contato entre professores e educadores ou pedagogos e pais é a oportunidade de crescimento coletivo de todos os envolvidos no processo, e quando esse contato não está sendo bem aproveitado, causará insatisfação. Mostra-se aí uma grande falha, pois a oportunidade que se tem de reunir e de conversar com os pais dos educandos não está sendo bem trabaIhada. Isso pode gerar um descontentamento maior com a escola. Nesse sentido, o Pedagogo precisa ser um profissional polivalente ao desenvolver sua prática, tornando-a significativa para o desenvolvimento de uma educação de qualidade para todos, tendo em vista o contexto socioeconômico brasileiro.
Enfim, o trabalho do Pedagogo influencia diretamente no dia a dia de educadores e educandos. Saber mediar as práticas do professor não é tarefa fácil; exige do pedagogo uma avaliação sistematizada e constante da atuação do docente, dentre outras questões relevantes para a atividade didático-pedagógica.

\section{Considerações Finals}

A escola está inserida em conflitos sociais. Necessita-se de um grupo que articule seus diversos segmentos em torno de um ideal de escola que se quer. O pedagogo surge como um elemento mediador e, ao mesmo tempo, instigador de práticas educativas capazes de transformar a educação.

O Pedagogo que atua na educação profissional precisa ter, além do conhecimento básico sobre a escola, conhecimento sobre a legislação que a rege e sobre o desenvolvimento humano, além de habilidades e competências, tais como: ser pesquisador da realidade escolar; ser capaz de fazer a releitura do seu cotidiano, de promover mudanças necessárias - enfatizando para isso o trabalho cooperativo, criando novos horizontes e possibilidades para a escola -, de abrir possibilidade de diálogo entre o grupo, de orientar seus colegas na construção coletiva da proposta pedagógica que dará identidade à escola; ter competência teórica para orientar o processo pedagógico na escola; enfim, ser articulador do processo pedagógico e da construção do Projeto Pedagógico dos Cursos.

Por fim, cabe ao pedagogo que atua na educação profissional promover e possibilitar um trabalho que garanta a qualidade do ensino, incentivando e motivando todos os segmentos da comunidade escolar, a vivência das práticas pedagógicas significativas, para que o aluno e o professor possam sentir-se satisfeitos com a educação tecnológica e profissional da qual fazem parte.

\section{ReferênCias}

ANDRÉ, Marli Elisa Dalmazo Afonso de. Etnografia da
prática escolar. Campinas, SP: Papirus, 1995.

BRZEZINSKI, Iria. Pedagogia, pedagogos e formação de professores: Busca e movimento. Campinas: Papirus, 1996.

DEMO, Pedro. Participação é Conquista: noções de política social participativa. 4 ed. São Paulo: Cortez, 1999. 
COBRA, Rubem Queiroz. Boas-maneiras, etiqueta e cerimonial: suas definições e seu lugar na Filosofia. Editora Valci Ltda., Brasília, 2002.

FREIRE, Paulo. Pedagogia da Autonomia: saberes necessários à prática educativa. São Paulo: Paz e Terra, 1997.

Educação e mudança. Trad.: Moacir Gadotti e Linia Lopes Martin. Rio de Janeiro: Paz e Terra, 1979.

GADOTTI, Moacir. Perspectivas atuais da educação. Porto Alegre: Artes Médicas Sul, 2000.

BEISIEGEL, Celso de Rui. A qualidade do ensino na escola pública. Brasília: Liber Livro Editora, 2006.

LÜDKE, Menga. ANDRÉ, Marli Elisa Dalmazo Afonso de. Pesquisa em Educação: abordagens qualitativas. São Paulo: EPU, 1986.

MACEDO, Roberto Sidnei. Etnopesquisa-crítica, Etnopesquisa-formação. Brasília:Líber, 2006.

MEDINA, Antonia da Silva. Supervisor Escolar: parceiro político pedagógico do professor. In: In: SILVA Jr, Celestino Alves; RANGEL, Mary (orgs.). Nove olhares sobre a supervisão. Campinas: Papirus, 1997. p.09-35.

KUENZER, Acácia Zeneida. Formação de profissionais da educação no Brasil: as políticas de formação: A constituição da identidade do professor sobrante. Educação \& Sociedade, Campinas, ano 20, n. 68, p. 163-183, dez. 1999.

MORAES, Maria Cândida. Educar na biologia do amor e da solidariedade. Petrópolis/RJ: Vozes, 2003.

ORSOLON, Luzia Angelina Marino. O coordenador/formador como um dos agentes de transformação da/ na escola. In: PLACCO, Vera Maria Nigro de Souza e ALMEIDA, Laurinda Ramalho de (org.). O coordenador pedagógico e o espaço da mudança. 3. ed. São Paulo: Loyola, 2003.

PARO, Vitor Henrique. Políticas educacionais: considerações sobre o discurso genérico e a abstração da realidade. In: Paro Vitor Henrique. Escritos sobre educação. São Paulo: Xamã; 2001. p. 121-39.

PLACCO, Vera Maria Nigro de Souza. Formação e prática do educador e do orientador. São Paulo: Papirus, 1994.
SEVERINO, Antônio Joaquim. Preparação técnica e formação ético-política dos professores In: BARBOSA, Raquel Lazzari Leite (Org.). Formação de Educadores: Desafios e Perspectivas. São Paulo: Editora UNESP, 2003, p.71-89.

VILLAS BOAS, Benigna Maria Freitas. Projeto de intervenção na escola: mantendo a aprendizagem em dias. Campinas:Papirus, 2006.

YIN, Robert K. Estudo de caso: planejamento e métodos. Porto Alegre: Bookman, 2004. 